\title{
Compartilhando experiências com aplicativos de acessibilidade na Educação Inclusiva.
}

\section{Share experience with app`s at Inclusive Education}

\section{aplicativos, educação inclusiva, design}

Esta pesquisa tem como objetivo principal adaptar ao contexto educacional inclusivo um serviço de design enquanto gestor e divulgador de informações e conhecimentos sobre usos e experiências de aplicativos de acessibilidade como recursos didáticos. Optou-se, no entanto, por uma metodologia exploratórioexplicativa a respeito da interatividade na educação e do potencial de aprendizagem dessas ferramentas. Já os resultados esperados apontam para mais projetos com responsabilidade social, voltados para a interdisciplinaridade e para a política educacional na inclusão.

\section{App`s, inclusive education, design}

This research has as main objective to adapt to the inclusive educational context a design service as manager of information and knowledge about uses and experiences of accessibility applications as didactic resources. However, it was opted for an exploratory-explanatory methodology regarding interactivity in education and the learning potential of accessibility applications. The expected results point to more projects with social responsibility, focused on interdisciplinarity and on educational policy in inclusion.

\section{Larissa Buenano Ribeiro}

\section{Introdução}

Valores já presentes na vida em sociedade são potencializados com a cultura da conexão que permite que nos organizemos de maneira mais rápida e democrática, e que trabalhemos nosso excedente cognitivo e perceptivo em projetos que façam parte dessa cultura colaborativa e participativa. Estas características conferem um significado peculiar às experiências vividas no espaço virtual e em suas práticas relacionais. Neste artigo discutiremos a presença destes valores na literatura acadêmica da área, bem como a sua influência nas ações dos sujeitos online, traçando as bases que nos permitirão abordar mais especificamente modos de estimular o uso e a divulgação dos aplicativos como propostas pedagógicas para aulas mais inclusivas.

Antes, o grande dilema da contemporaneidade, segundo Giardelli (2012), era o que a tecnologia poderia fazer pelas pessoas? Agora, o autor muda de questionamento ao se perguntar sobre o que as pessoas podem e estão fazendo com a tecnologia? Estamos vivenciando a era participativa, na qual é necessário repensar as relações humanas e realinhar nossos objetivos como indivíduos digitais.

Esta era, um tanto colaborativa e em conexão, é marcada sobre pessoas individualmente livres e voluntariamente juntas, e um dos maiores avanços do século XXI tem sido o aparecimento do lado cooperativo das coisas, unindo o digital ao social por meio da transparência e da exposição de novas ideias e abordagens que conseguem contribuir e mudar muitas realidades.

Estes conceitos e iniciativas coletivas surgiram como uma interessante ferramenta projetual na medida em que são práticas cujo sucesso depende fundamentalmente da capacidade do projetista em mobilizar sujeitos dispostos a colaborar com ele num empreendimento ou serviço diferente, numa experiência diferente.

Acredita-se que os processos colaborativos online são marcados por uma possibilidade de organização rápida e de respostas instantâneas para realização de grandes atos coletivos. Pergunta-se então, como esta nova carga cognitiva e perceptiva afeta as oportunidades da existência e do funcionamento de processos colaborativos? O que se altera na mobilização dos sujeitos para apoiar uma causa ou um projeto? E se existe algo de novo neste processo ou apenas um avanço tecnológico oriundo da cultura da conexão?

Visando responder estas questões que fundamentarão o mapeamento de aplicativos como propostas pedagógicas na sociedade da cultura da conexão, pensadas, principalmente, em um serviço que é essencialmente relacional, colaborativo e participativo. Em detrimento de uma

Anais do 8 CIDI e 8 CONGIC

Guilherme Santa Rosa; Cristina Portugal (orgs.)

Sociedade Brasileira de Design da Informação - SBDI

Natal | Brasil | 2017

ISBN 978-85-212-1305-5
Proceedings of the $8^{\text {th }} \mathrm{CIDI}$ and $8^{\text {th }}$ CONGIC

Guilherme Santa Rosa; Cristina Portugal (orgs.)

Sociedade Brasileira de Design da Informação - SBDI

Natal| Brazil | 2017

ISBN 978-85-212-1305-5 
necessária mobilização de vontades e desejos dos professores, formadores e gestores das instituições de ensino, transformadas em atos de um fazer pelas aulas inclusivas, e de um agir em face da convocação à ação de inclusão, a partir da troca, do compartilhamento e da divulgação de experiências de mudança.

\section{Ideação: uma nova lógica de educação inclusiva associada aos aplicativos de acessibilidade}

A percepção visual ocasionada pelo mapeamento dos aplicativos de acessibilidade envolve a habilidade de ver e de dar significado as suas representações gráficas. A partir do momento em que algo se torna visível e organizado para os professores que atuam na Educação Inclusiva, as suas cognições conseguem captar isto, associando o que se vê aos conhecimentos prévios do repertório, ou seja, o observador se aproxima do entendimento do que é este algo, do que é este serviço informativo.

A percepção visual lida com a reação inicial do usuário em relação aos símbolos mapeados, enquanto que a cognição lida não apenas com a percepção visual, mas também com os processos de raciocínio, de experiência e de memória dos usuários.

Como forma de proposição acerca da maneira de se analisar o que influencia o usuário professor em um mapeamento de aplicativos até então desconhecidos por eles, considerando nesse contexto de contato, que a percepção visual do professor deve ser tomada como uma forma de "entrada" para as análises da interação professor-mapa de aplicativos.

De uma maneira geral, as pessoas reagem de forma diferente aos estímulos visuais, já que a informação é recebida de uma única vez, ao invés, por exemplo, do processo de percepção de informações faladas ou escritas, que ocorrem de forma sequencial e em ordem definida. Portanto, o entendimento de símbolos mapeados é afetado por variáveis visuais absolutas (localização, cor, forma, tamanho, orientação, entre outras) e relativas (a variação visual em função dos outros elementos do mapa). De acordo com Bertin (1967), a variável localização, que no caso do mapeamento de aplicativos vai ser a segmentação por deficiência e por cor, ou seja, a deficiência visual, a título de explicação, é dominante sobre todas as outras, no sentido de que essa localização é o único atributo que todo o aplicativo para deficientes visuais compartilha no mapeamento, tornando-se uma variável ótima para que sejam representadas correspondências da mesma cor, tais como a localização para aplicativos direcionados aos deficientes auditivos em outra cor e a localização para os com mobilidade reduzida, representados com uma cor distinta das outras duas cores, cunhando os três eixos do repositório de aplicativos aqui idealizado e aqui mapeado.

No mapeamento optou-se por aqueles aplicativos de acessibilidade que apresentavam interfaces intuitivas e fáceis, coerentes aos critérios de usabilidade e de acessibilidade, adaptação ao usuário; aceitação; resistência e segurança; satisfação; e tempo de navegação, com as quais os professores não tivessem dificuldades em sua interação e em sua aplicação de adaptações nas atividades pedagógicas.

Além do mais, optou-se por aplicativos que auxiliavam várias atividades didáticas entre os professores e alunos com necessidades educacionais especiais, tais como os aplicativos direcionados para ajudar na efetivação da comunicação entre os envolvidos, uma vez que a comunicação é a porta para distribuir, para alcançar, para ensinar e para apreender conhecimentos/exercícios de diversas matérias.

Em vista disso buscaram-se, principalmente, os aplicativos que proporcionavam uma aproximação comunicacional tanto ao Braille e aos sintetizadores de voz, quanto a linguagem em Libras, exemplificados pelo: Hand Talk'; ProDeaf; Vlibras ${ }^{3}$; BrailleAppFree ${ }^{4}$; Aipoly Vison ${ }^{5}$; Ubook ; Ereader Prestigio ${ }^{7}$; Talback ${ }^{8}$; Voice Over ${ }^{9}$; e Cozy Magnifier ${ }^{10}$.

\footnotetext{
${ }^{1}$ Aplicativo que traduz automaticamente textos e áudios para a língua de sinais.

2 Semelhante ao aplicativo Hand Talk atuando como tradutor simultâneo de Libras.

3 É outro aplicativo tradutor de textos e áudios em Libras, tendo na sua configuração a opção do regionalismo.
} 
Justificando essa vertente projetual pelo fato de que não existem muitos materiais didáticos adaptados as linguagens dominadas pelos os alunos com necessidades educacionais especiais. É preciso, entretanto, incentivar pelos aplicativos e pelas tecnologias já existentes práticas que comuniquem os conteúdos para todos os alunos. Interpretando os aplicativos de tradução para a Libras e para o Braille, como os dicionários de "idiomas estrangeiros", que deixam o professor mais seguro para ora se comunicar com os seus alunos sobre determinado assunto, ora tirar dúvidas sobre algum termo, número, letra ou palavra.

Já os aplicativos selecionados para os alunos com mobilidade reduzida são concentrados no alcance desses estudantes aos ambientes escolares, buscando ilustrar e estruturar de forma acessível o acesso às escolas e as salas de aula bem como a adequação espacial das próprias salas de aula atribuídas a esses alunos, exemplificados pelo: Guia de Rodas ${ }^{11}$ e Cidadera $^{12}$.

No mapeamento encontrado na figura 1, consta a segmentação por deficiência, na qual a cor azul é destinada para deficiência visual, a cor laranja para deficiência auditiva e a cor rosa para mobilidade reduzida; além de uma marcação para identificar se o aplicativo é pago ou gratuito e se ele é encontrado tanto para Android quanto para iOS, utilizando o mesmo artifício de cores para identificá-los e diferenciá-los.

Figura 1- Mapeamento dos aplicativos
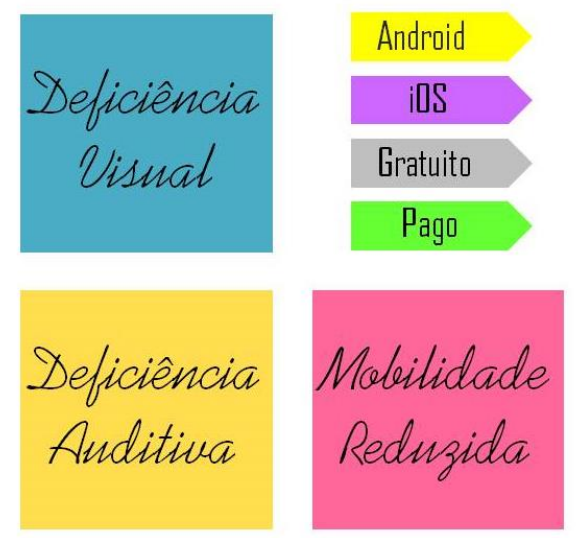

\footnotetext{
${ }^{4}$ Aplicativo que converte texto em Braille e vice-versa, além de ensinar o alfabeto, pontuação e números em Braille.

${ }^{5}$ Aplicativo que transforma imagens e as cores dessas imagens em sons, reconhecendo mil itens em sua versão gratuita.

${ }^{6}$ É um aplicativo em forma de uma "audioteca" com grande acervo de livros em áudio.

7 Também é um aplicativo com vários livros audíveis.

8 Leitor de tela do Android.

9 Leitor de tela do iOS.

${ }^{10}$ Aplicativo que converte o telefone em lupa e lanterna.

${ }^{11}$ Aplicativo que identifica e promove informações de acessibilidade para pessoas com dificuldade de locomoção visando uma vida mais autônoma e inclusiva

12 Aplicativo para denunciar os problemas das cidades tais como mobilidade urbana, calçadas irregulares ou obstruídas, oferecendo ainda a oportunidade das pessoas endossarem as reclamações dos demais usuários e divulgá-las nas redes sociais.
} 

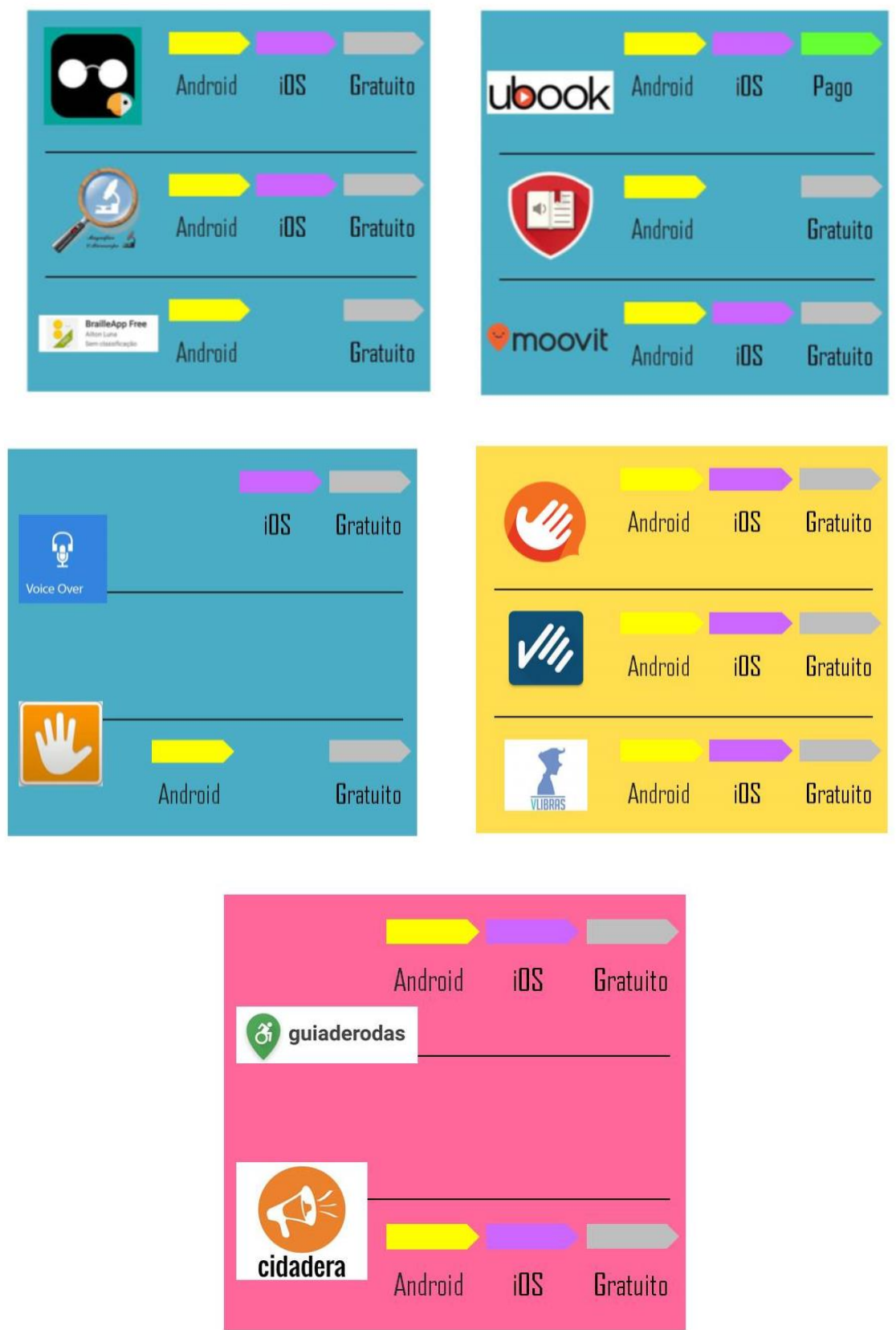

Fonte: elaborado pela autora.

\section{Curta, compartilhe e faça parte de uma ação coletiva de inclusão na educação!}

A dinâmica para participar de uma ação de inclusão na educação se inicia no encontro interdisciplinar e na condição de possibilidades para a ampliação do repertório dos professores sobre os aplicativos e sobre as funções dos seus próprios smartphones e tablets a fim de quebrar os limites e as fronteiras de usos convencionais para gerar interseções entre a educação, a comunicação e a tecnologia por meio da inteligência coletiva.

É nesse momento que o designer situa o professor sobre as ferramentas e os aplicativos a sua volta, sobre as pesquisas tecnológicas e sobre a cultura da conexão, que permite a construção de uma rede cooperativa entre professores e formadores que atuam na educação inclusiva. Preocupando-se em ativar vínculos e relações, e em aproximar as linguagens acadêmicas, pedagógicas, metodológicas e os termos técnicos ao ambiente de uma sala de aula com alunos com necessidades educacionais especiais. 
Essa rede de cooperação tem o intuito de gerar uma coesão no coletivo, na qual não existam detentores de soluções ou conhecimentos e sim pessoas motivadas para a produção de saídas em determinados campos problemáticos da educação inclusiva. É aqui que se estabelece a etapa de como divulgar, de como comunicar e de como afetar e ser afetado pelas ações de inclusão associadas aos aplicativos de acessibilidade como recurso didático.

O meio escolhido para a socialização da composição de conteúdos e para as sugestões pedagógicas de uso dos aplicativos de acessibilidade nas aulas regulares, foi uma apresentação em formato de revista digital em uma turma de 80 professores que atuam em escolas estaduais com alunos com necessidades especiais na Zona Leste de São Paulo, na qual a sua composição visual faz alusão aos post it e aos marcadores coloridos de matéria que cotidianamente organizam os estudos dos professores.

Tais elementos aproximam metaforicamente os seus estudos físicos sobre um conteúdo novo, dos estudos e das leituras de novos conteúdos no meio digital. Contendo através desse conceito na revista uma ferramenta já conhecida dos professores que é o checklist ou relatório para monitorar o desempenho dos alunos na atividade, organizando e documentando os seus avanços no semestre, e contendo também na revista os aplicativos associados aos seus links para o alcance e o acesso direto as lojas online, caso o professor tenha interesse em utilizá-los no momento em que lê e aprende com a revista digital.

Após a apresentação oral da revista na turma, foi ocasionado, quase que instantaneamente, muito interesse dos professores pelos aplicativos, gerando também muitos relatos e debates sobre o desconhecimento dessas ferramentas e sobre a falta de iniciativa e de comportamento em buscar adaptações curriculares e estratégias pedagógicas nos aplicativos, e principalmente, resultando como conclusão de debate pelas falas dos próprios professores e formadores, como os aplicativos agora que já são reconhecidos por eles, podem ser considerados mais um caminho alternativo a ser explorado e estudado para auxiliar nas práticas educacionais relacionadas à inclusão dos alunos.

A grande maioria dos professores baixou, sem hesitar, os aplicativos de seu interesse e de seus nichos de atuação, correspondentes aos tipos de necessidades educacionais dos seus alunos. Além desse fato, um debate maior sobre os aplicativos tradutores de Libras foi provocado, surtindo análises de professores que dominavam a língua brasileira de sinais e que já atuavam com alunos surdos em suas turmas, a fim de eleger o aplicativo mais bem desenvolvido para as atividades didáticas nessa modalidade de deficiência, sendo o "Hand Talk", o app escolhido e eleito pelos professores especializados como o melhor.

Outro debate de grande importância que foi estimulado e bem mencionado durante a apresentação oral abrangeu a necessidade de gravar livros, resumos ou provas com a voz dos próprios professores ou com um elenco de pessoas que já socializam com os alunos com deficiência visual nas aulas. Com o intuito de gerar conteúdos didáticos com potencial acolhedor, afetivo e bem mais agradável do que as vozes dos leitores de tela. Sugeriu-se nessa conversa até os aplicativos de áudio ou o próprio áudio do Whatsapp para essa prática de produções de ensino e de aprendizagem audíveis. Foi levantado, entretanto nessa discussão, a praticidade gerada a esses alunos e a todos os alunos que poderiam ouvir os "conteaudistas" (conteúdos em áudios) quando quisessem ou tivessem dúvidas sobre os temas abordados nas produções.

Todas as sugestões pensadas e produzidas pelos professores na dinâmica de interação com os aplicativos presentes e explicados na revista digital, resultou em identificar o grande potencial que as ferramentas tecnológicas permitem quando em contato com os propósitos certos e com as pessoas certas. Foi fato que os professores conseguiram visualizar cada aplicativo como se fossem um lápis, um caderno, um quadro, um livro, um powerpoint ou qualquer outro objeto didático que os auxiliassem a passar seus conhecimentos paras os seus alunos com necessidades educacionais especiais. Eles pensaram e estruturam as atividades $\mathrm{e}$ as adaptações inclusivas com principio, meio e fim, com causas e consequências que levavam esses alunos com necessidades educacionais especiais a passarem de ano, a chegarem as suas escolas, a aprenderem os conteúdos programáticos e a entenderem que inclusão só tem sentido para os professores quando eles ensinam todos os seus alunos.

Outra vertente interessante para a análise das sugestões pedagógicas aqui levantadas foi o interpretar otimista dos professores nos aplicativos gratuitos, as possibilidades de adaptar provas para pessoas com baixa visão sem o custo da impressão ampliada; os chamados por 
eles de "aplicativos dicionários" que traduziram Libras e Braille para português, os deixando mais seguros e mais confiantes na efetivação da comunicação e na proposição de atividades para os alunos surdos ou para os alunos cegos; as avaliações de acessibilidade dos caminhos para que os alunos com mobilidade reduzida conseguissem chegar às suas aulas. Realmente, as sugestões pedagógicas idealizadas pelos professores foram melhores do que a gente esperava e nem sequer imaginava.

Os "muito obrigado" dos professores por terem acesso a mais um possível caminho para a inclusão dos seus alunos com necessidades educacionais especiais estão guardados nas memórias dos pesquisadores. Mas com certeza, nas memórias dos alunos desses professores vão ficar agradecimentos com muito mais gratidão e com muito mais significado.

Em vista disso, falamos para os professores participantes que o comportamento de visualizar uma informação sobre ações de inclusão na educação, de elogiar, de concordar e de perguntar sobre um assunto quando lhe é apresentado em sala de aula como eles já estão ambientados, poderia também ser feito nas redes sociais expandindo mais ainda o território e o alcance da sua ação de inclusão, onde o curtir significaria concordar, o compartilhar significaria que aquela informação precisaria ser vista além dos amigos que a pessoa que postou conhece e 0 comentar poderia ser condicionado tanto para os elogios como para as perguntas ou para os debates sobre a postagem.

Para que assim, as postagens nas redes sociais servissem de modelo e estímulo para que os professores continuassem compartilhando suas ações e saberes de inclusão com mais e mais professores, compreendendo que além de aprender, de ensinar e de contribuir com as suas postagens e as postagens dos outros, eles poderiam ser a informação sobre inclusão e formar mais informações de inclusão.

\section{Conclusão}

Ao buscar respostas para as necessidades dos alunos especiais em aplicativos criteriosamente identificados, estaremos também, mapeando as potencialidades e as dificuldades dos alunos em diferentes níveis, respeitando cada diversidade e as segmentando por deficiência. Este mapeamento pode orientar ações e estratégias de inovação que se adaptem a várias escolas, auxiliando nas aulas inclusivas e planejando formas de estimular e dialogar favoravelmente as relações que se constituem em torno dos aplicativos, dos professores, das famílias e dos alunos com necessidades educacionais especiais.

Além do mais, foi percebido e foi constatado que as produções tecnológicas de aplicativos com funções acessíveis não estavam levando em conta as divulgações desses serviços para a educação inclusiva, o fácil acesso desses aplicativos nas lojas online, e, principalmente, as suas possíveis extensões funcionais em atividades didático-pedagógicas para a grande parcela de professores que lida diariamente com alunos com necessidades educacionais especiais. Em outras palavras, os aplicativos precisam chegar em quem precisa e também em quem ensina e convive com quem precisa.

A diversidade de percepções e pontos de vistas dos professores envolvidos na produção das sugestões por meio do seu olhar pedagógico diante dos aplicativos de acessibilidade pode construir uma fonte enriquecedora de informações sobre a ação coletiva e a ação colaborativa na educação inclusiva.

O desenvolvimento dessa rede didático-inclusiva entre os professores também foi essencial para promover a conectividade, a confiança e o domínio de novas tecnologias. Já que eles viam em seu semelhante uma motivação para trabalhar, para interagir e para pesquisar de forma conjunta novas maneiras de tornar as suas aulas mais inclusivas.

Neste projeto, existe a vontade de mudança, assim como existem métodos e estratégias produtivas para a educação inclusiva ao redor dos aplicativos de acessibilidade. O que falta é um meio efetivo de mapeamento, de divulgação, de engajamento e de aplicação de tais ideias, além de um maior diálogo entre profissionais da área para que possam trocar histórias, compartilhar experiências e crescer juntos em prol da educação inclusiva. 


\section{Referências}

BERTIN, Jacques. Sémiologie Graphique: les diagrammes, les réseaux, les cartes. Paris:Mounton e Gauthier-Villars. 1967.

FERRARI, Pollyana. Comunicação digital na era da participação. [recurso eletrônico] / Pollyana Ferrari. Porto Alegre, RS: Editora Fi, 2016.

GIARDELLI, Gil. Você é o que você compartilha: e-agora: como aproveitar as oportunidades de vida e trabalho na sociedade em rede. São Paulo: Ed. Gente, 2012.

KRUCKEN, Lia. Design e território: valorização de identidades e produtos locais. São Paulo: Studio Nobel, 2009.

MANOVICH, Lev. The Language of New Media. Cambridge, MA: MIT Press, 2000.

NORMAN, Donald. A. O design do Dia-a-Dia. Donald A. Norman; Tradução de Ana Deiró. Rio de Janeiro: Rooco, 2002.

. O design do Futuro. Donald A. Norman; Tradução de Talita Rodrigues. Rio de Janeiro: Rooco, 2010.

PINHEIRO, Tennyson. Design Thinking Brasil: empatia, colaboração e experimentação para pessoas, negócios e sociedade. Rio de Janeiro: Elsevier, 2011.

The Service Startup: design gets lean. Inovação e Empreendedorismo por meio do design. Rio de Janeiro: Alta Books, 2015.

Lojas online de aplicativos. Disponível em: itunes.apple.com; play.google.com

\section{Sobre o(a/s) autor(a/es)}

Larissa Buenano Ribeiro ; Msc, PUC-SP, Brasil <lalibuenano@gmail.com> 